\title{
RELACIONES SEMÁNTICAS DE COMPONENTE POTENCIAL Y CONSTANTE DEL ESTILO ADMINISTRATIVO JURÍDICO DESDE LA PERSPECTIVA CONTRASTIVA
}

\author{
Jana PEŠKOVÁ \\ Universidad de Bohemia del Sur, České Budějovice
}

\begin{abstract}
En): The aim of this paper is to show how the semantic relations (synonymy and polysemy) are performed in professional texts (administrative - legal). Firstly, we will try to demonstrate the suitability of the distinction between potential components and the constant components of professional vocabulary to subsequently reveal different skills of the dichotomic constituents presented at the time of establishing the semantic relationships in legal texts of various degrees of speciality. In the final part of this article, given the plurality and diversity of legal systems between Spanish speaking countries and the Czech Republic, we study this problem through a contrastive approach (extra-linguistic synonymy).
\end{abstract}

Keywords (En): constant components; contrastive approach; extra-linguistic synonymy; intralinguistic synonymy; legal texts; polysemy; potential components; Spanish.

\section{Introducción}

El objetivo del presente artículo es mostrar cómo se realizan las relaciones semánticas (sinonimia y polisemia) en textos especializados (administrativojurídicos). El tema de la sinonimia y polisemia en textos jurídicos no suele ser un problema muy discutido. La explicación parece ser sencilla: la sinonimia y polisemia no tienen (ni deberían tener) cabida en un género tan específico como lo es el lenguaje jurídico. Sin embargo, la cuestión no es tan clara y cabe ser contemplada desde una perspectiva más amplia. A nuestro modo de ver, el problema de las relaciones semánticas en el lenguaje jurídico estará en la estrecha relación con el carácter heterogéneo de las unidades léxicas que constituyen el texto especializado; y además de ello, se someterá, en muchos casos, al tipo y al grado de especialidad del género jurídico. Partiendo de ese marco teórico, intentaremos: en primer lugar, manifestar la idoneidad de la distinción entre componentes potenciales y componentes constantes del léxico especializado (capítulo 3) para poder, posteriormente, enseñar la diferente aptitud de los constituyentes de la dicotomía presentada a la hora de establecer las relaciones semánticas en textos jurídicos de distinto grado de especialidad (3.1.1. y 3.1.2.). Nos centraremos en la descripción de las relaciones semánticas en textos jurídicos españoles y checos (sinonimia intralingüística) ${ }^{1}$ y por último, en la parte final del presente artículo (capítulo 4), dada la pluralidad y diversidad de los sistemas legales entre los países de habla hispana y la República Checa, estudiaremos dicho problema a través de un enfoque contrastivo (sinonimia extralingüística).

\section{Definición del lenguaje especializado (jurídico)}

Ya que a lo largo del presente artículo utilizaremos en varias ocasiones el concepto de lenguaje especializado, consideramos oportuno aclarar qué entenderemos bajo esa etiqueta. En primer lugar, el lenguaje especializado lo

\footnotetext{
${ }^{1}$ Los ejemplos ilustrativos que utilizamos a lo largo de los capítulos 3 y 4 han sido tomados de documentos jurídicos auténticos (autos, sentencias, etc.) de cuya facilitación agradezco a la profesora Susana Cruces Colado de la Universidad de Vigo. 
contraponemos al lenguaje común. Las diferencias entre el lenguaje común y el especializado las percibimos ante todo en dos niveles lingüísticos, o sea, en el morfosintáctico y en el lexical. Queda claro que ambas variantes lingüísticas (tanto el lenguaje común como el especializado) comparten varias características comunes. Sin embargo, hay ciertos recursos de expresión cuya presencia es más probable tan solo en una de las dos variantes. Al igual que el uso de elementos de habla familiar o coloquial (p. e. uso de expresiones populares, vulgarismos) será poco frecuente en el discurso técnico-científico, podemos constatar que la utilización de ciertas estructuras gramaticales o de ciertas unidades léxicas (por ejemplo futuro de subjuntivo; uso de tecnolecto) será muy restringido en el habla común, a excepción de situaciones en las que esos usos se someten a factores estilísticos o situacionales. DUBSKÝ (1984b, 1989), a nuestro juicio acertadamente, distingue entre los componentes constantes (terminológicos) del estilo especializado, o sea, toda la terminología propia de un ámbito profesional cuya presencia es conditione sina qua non puede existir un texto (estilo) especializado y entre los componentes potenciales (no terminológicos) cuya presencia, por otra parte, no es conditione sina qua non puede existir un texto (estilo) especializado, sin embargo cuya función principal consiste en marcar estilísticamente el estilo funcional en cuestión. Así pues, el léxico de un estilo especializado se caracteriza, por un lado, por una abundante presencia de términos $\mathrm{y}$, por otro lado, por componentes de carácter no terminológico cuyo uso en el lenguaje común es limitado (aunque no imposible). Es muy parecido a lo que dice BARCELó MARTÍNEZ (2010 : 30):

« [...] las lenguas especializadas son aquellas, que sin ser distintas en esencia de las lenguas generales en las que se insertan por compartir con ellas rasgos fundamentales de tipo fonológico, morfológico, sintáctico y gramatical, se caracterizan por su uso frecuente en un determinado ámbito especializado ».

A nuestro modo de ver, el texto especializado más prototípico (o ideal) es, entonces, caracterizado como la coexistencia de elementos terminológicos (términos) y elementos potenciales (no terminológicos). El grado máximo de lo que acabamos de exponer lo representan, sobre todo, los textos con alto nivel de especialización como por ejemplo los textos jurídicos escritos por juristas para juristas. Para alcanzar el mayor grado de formalización textual es, además, imprescindible que se trate de textos convencionales (sentencia, auto, ley etc.), donde se puede presuponer cierta formalización textual que va mano a mano con la preferencia de los recursos estilísticamente marcados (componente potencial) frente a los recursos estilísticamente neutrales, y con una abundante frecuencia de cierta terminología propia (componente constante).

Ejemplo de un fragmento de texto de contenido jurídico de alto grado de especialidad (formulario jurídico auténtico):

[...] Por el Ministerio Fiscal la/s defensa/s de el/los imputado/s se ha evacuado el traslado conferido para que solicitaran el sobreseimiento de la causa o apertura del juicio oral, formulando todas las partes escritas solicitando el sobreseimiento de las actuaciones. [...] 
Ejemplo de un fragmento de texto de contenido jurídico de grado de especialidad inferior (noticia de Internet ${ }^{2}$ ):

[...] El juez de la Octava Sala de la Cámara Penal del Juzgado de Primera Instancia del Distrito Nacional, Teófilo Andújar Sánchez, dispuso su inmediata puesta en libertad, desde la sala de audiencias, por prisión ilegal. [...]

\section{3. ¿Hay lugar de sinonimia en el lenguaje jurídico, campo tan especializado, cuyo objetivo es la falta de ambigüedad?}

La presencia de sinonimia y polisemia, aunque sean más propias del lenguaje común, es innegable también en el ámbito del léxico especializado, como pretendemos revelar en el presente artículo. En primer lugar, pretendemos demostrar que la monosemia y la monorreferrencialiad (p.e.: CALVI, $2010: 25$ ), o sea, las etiquetas que se suelen vincular con la terminología especializada, no siempre se revelan de maneras tan evidentes y claras como pueda parecer a primera vista; y que, por lo tanto, la sinonimia (y polisemia) tienen su lugar en el lenguaje especializado. Para ello, suponemos que la sinonimia se manifestará de manera diferente en cada uno de los dos componentes del lenguaje especializado (componente potencial y constante), según hemos sugerido al principio.

\subsection{Sinonimia intralingüística}

\subsubsection{Sinonimia de componentes potenciales}

Tal y como apunta DUBSKÝ (1984b : 29), « llamamos componente potencial del estilo funcional especializado a los medios de expresión tomados de la lengua común o utilizados en otros estilos funcionales cuyo uso no es indispensable en el estilo funcional en cuestión, sino solamente posible, potencial ». De tal modo, formarán una parte de este grupo del lenguaje especializado por ejemplo, « las unidades léxicas que sirven de lazo de unión entre las unidades constantes » y también algunas « estructuras gramaticales que contribuyen a dar al texto su forma ordenada ». Hasta cierta medida es posible asemejar lo que Dubský denomina como componente potencial de léxico especializado con el vocabulario relacional de una clasificación posterior del léxico especializado de ALCARAZ (2004), o sea, tales unidades léxicas que sirven como enlaces entre los conceptos y unidades léxicas de un determinado texto especializado.

En primer lugar, cabe subrayar que, a nuestro juicio, la elección entre una forma estilísticamente marcada (componente potencial) u otra neutral depende, en la mayoría de casos, de estos factores principales: las preferencias individuales del autor, del grado de la cortesía y/o de las convenciones del estilo funcional cuestionado. Así es el caso de, por ejemplo, verbos que expresan la función de modalidad epistémica en el discurso científico (necesidad, obligación): hay que decir (estilísticamente neutral) :: cabe decir (estilísticamente marcado) o de verbos en función del predicado verbonominal: es indispensable (estilísticamente neutral) :: resulta indispensable (estilísticamente marcado). Entre otros recursos

\footnotetext{
${ }^{2}$ http://www.diariolibre.com/noticias/2014/07/14/i699461_recluso-declarado-muerto-hace-puestolibertad.html [Fecha de consulta: 20/08/2014].
} 
estilísticamente marcados en el lenguaje especializado pertenecen varios casos de despersonalización expresados a través de diferentes maneras: nos hemos equivocado (estilísticamente neutral) :: se ha cometido un error (estilísticamente marcado), o diferentes casos de nominalización: medir (estilísticamente neutral) :: hacer la medición (estilísticamente marcado). ${ }^{3}$ Dichos ejemplos los podemos descubrir también dentro del ámbito jurídico-administrativo, de cuyo análisis nos ocuparemos en las siguientes líneas.

En primer lugar, hay que tener en consideración la estrecha relación que existe entre la función y tipología del texto especializado y el carácter de sus constituyentes correspondientes. En consecuencia de lo cual se puede presuponer una frecuencia más alta de componentes potenciales que implican cortesía en diferentes tipos de escritos jurídico-administrativos (exhorto, poder notarial, solicitud de habeas corpus), ante todo en las partes textuales con predominante función persuasiva; y su frecuencia inferior en textos puramente legislativos (leyes, decretos) ante todo en las partes textuales con predominante función expositiva. De ahí podemos justificar, que los escritos jurídicos dan preferencia a unas formulaciones estilísticamente más expresivas y marcadas, como por ejemplo dar fe, a diferencia de la más neutral certificar en el siguiente caso:

1. El día ante mí compareció personalmente el señor quien doy fe de conocer y [...].

Sin duda alguna, los factores que acabamos de exponer no son los únicos que influyen a la hora de elegir entre dos unidades léxicas aparentemente sinónimas. En el ámbito jurídico somos frecuentemente testigos de la presencia de varias estructuras "preestablecidas", cuya reiterada utilización en un determinado contexto suele llegar hacia cierta petrificación de dichas construcciones, convirtiéndolas en las así llamadas fórmulas estereotipadas (clichés automatizados), que ya para algunos autores (KOPECKIJ, 1935) formarían parte del componente constante del léxico especializado (ejemplos 2-4):

2. Póngase en conocimiento del Ministerio Fiscal y demás partes personadas y notifíquese al inculpado.

3. D. mayor de edad, con DNI $\mathrm{n}^{\circ}$ $\mathrm{y}$ domicilio en pone en conocimiento del Juzgado los siguientes hechos: [...].

4. Desconociendo quien pudo apoderarse de dicha copia de seguridad, y pudiéndose haber cometido un delito, pongo todo ello en conocimiento del Juzgado para que averigüe lo acontecido.

Queda claro que la expresión anterior (poner algo en conocimiento de alguien) podría ser sustituida por verbos estilísticamente menos marcados (anunciar, comunicar, avisar); no obstante, tal solución no se suele adoptar y la expresión del

\footnotetext{
${ }^{3}$ Es cuestión a la que no podemos (ni pretendemos) dar una explicación convincente ahora, si en tales casos sería admisible reflexionar acerca de la sinonimia de recursos morfosintácticos que sirven para expresar el mismo sentido.
} 
mismo contenido por medio de un recurso sinónimo podría ser considerada en esos casos como fenómeno más bien no deseable.

Los verbos caber y suplicar en los contextos que siguen nos sirven como otras manifestaciones de lo que acabamos de enseñar: sostenemos la opinión que en oposición a sus sinónimos más neutrales poder o solicitar, también los casos siguientes pueden ser considerados como usos "petrificados", "automatizados" de dichas formas, cuya sustitución por otras formas sinónimas no es que no sea posible, sino que no suele ser adoptada dadas las convenciones textuales del género cuestionado:

5. [...] contra la presente resolución no cabe recurso alguno [...].

6. Suplico al juzgado, tenga por presentado este escrito y sus copias, se sirva admitirlo, [...].

Ahora bien, estimamos bastante tenues las fronteras existentes entre una construcción que puede ser considerada hasta cierta medida como estereotipada y otra que no lo es. De ahí, que no es siempre muy fácil poder decidir si una unidad léxica puede ser sustituida por su variante más neutral o no, manteniéndose el mismo (o por menos parecido) valor enunciativo (7-9). Lógicamente, tales elementos constitutivos de un texto jurídico cobran una importante relevancia en el proceso traslativo, ya que el traductor debe ser (por lo menos) consciente de su "uso automatizado" que prácticamente descarta la posibilidad de sustituirlas por otras formas comparables desde el punto de vista funcional:

\section{Ante mí comparece [LLEGA] [...].}

8. Concedida la palabra manifiesta [DICE] [...].

9. El presente procedimiento se incoó [EMPEZÓ] por los hechos que resultan de las anteriores actuaciones, habiéndose practicado [REALIZADO] cuantas diligencias de investigación constan en los autos.

Antes bien, existen casos cuando hace falta distinguir consistentemente entre el componente potencial y constante, ya que este último puede ser expresado a través de recursos formalmente idénticos con los recursos del componente potencial: tales casos los encontramos por ejemplo en verbos que expresan "petición", donde por un lado tenemos verbos que se diferencian entre sí en el nivel de su uso neutral (10-11) y uso marcado (12) y, por otro lado, en textos jurídicos encontramos así mismo verbos (13-14) cuyo uso viene determinado por el contenido correspondiente al que refiere, y que es jurídicamente tan específico que su "sustitución" por un sinónimo llegaría a la expresión inexacta de la realidad jurídica correspondiente (el verbo funciona en tales casos como elemento terminológico, derivado de términos jurídicos concretos "requerimiento" y "exhorto", respectivamente). En tales casos la sinonimia ya sería considerada como fenómeno más que no deseable.

10. Por el Ministerio fiscal en el Procedimiento Abreviado $\mathrm{n}^{\circ}$ que se sigue en este Juzgado, se ha solicitado la apertura del Juicio Oral en el presente procedimiento. 
11. Que, habiéndoseme dado traslado de las actuaciones mediante fotocopia el día , mediante el presente escrito, en tiempo y forma y a tenor de lo preceptuado en el artículo 781.1 de la LECRIM, solicito la apertura de juicio oral, ante el Juzgado de lo Penal y contra D , [...].

12. El Fiscal interesa la apertura del juicio oral por el Juez de Instrucción al que se dirige este escrito.

13. En virtud de lo acordado en el juicio de faltas número $356 / 04$, ejecutoria número $25 / 06$, seguido en este Juzgado, por medio de la presente se requiere al condenado don José Miguel Ortega Hernández, para que en el plazo de tres días cumpla la pena de 30 días de multa a razón de 6 euros diarios, lo que hace un total de 180 euros, bajo apercibimiento de que si no lo satisficiere voluntariamente o por vía de apremio, se seguirá de acuerdo con lo previsto en el artículo 53 del Código.

14. No se le recibirá juramento. Tan solo se le exhortará a decir verdad y que debe responder de una manera precisa, clara y conforme a la verdad a las preguntas que le fueren hechas.

El empleo del componente potencial estilísticamente marcado en el lenguaje administrativo jurídico no incluye solamente la esfera de los verbos; existen numerosos casos de adverbios estilísticamente marcados (15-16), conjunciones (17) o perífrasis verbales (18-19). También aquí, hay que tener en consideración que su sustitución por un sinónimo puede ser estimado menos eficaz desde el punto de vista de la perlocución correspondiente y su uso lo relacionamos con los factores expuestos:

15. [...] lo único que perseguía era lucrarse con el dinero que pedía por anticipado.

16. Seguidamente se cumple lo acordado.

17. Ayer por uno de los técnicos de informática se me manifestó que los datos del programa se habían perdido, solicitándome la llave al objeto de poder introducir la copia de seguridad.

18. Con ello, se da por terminada la presente, que [...].

19. Se tienen por solicitadas las pruebas propuestas sobre cuya admisión resolverá en su día el órgano al que corresponda el enjuiciamiento.

Otro caso muy específico de la sinonimia en el lenguaje jurídico administrativo lo representan las construcciones con el predicado verbonominal. Nuestro objetivo aquí no consiste en hacer un análisis exhaustivo relativo a las cuestiones metodológicas acerca de su definición, su función en la lengua y las posibles diferencias entre ellas y entre las construcciones formalmente parecidas a ellas. Para tales fines aludiremos a la monografía de RADIMSKÝ (2010) y, junto con él, las definiremos como « spojení predikativního jména s kategoriálním slovesem » [unión entre el nombre predicativo con un verbo categorial; traducido por J.P.]. Ese verbo categorial en la mayoría de las construcciones verbonominales cumplirá mera función auxiliar (o de apoyo), mientras que el significado lexical de la construcción correspondiente se desprenderá del significado del sustantivo correspondiente. De hecho, podríamos relacionar su 
funcionamiento con el que revelan las perifrasis verbales, con la diferencia consistente en que mientras que las perífrasis verbales «stojí na přechodu mezi syntaktickými spojeními a analytickými tvary morfologickými » [se encuentran en mitad de camino entre las uniones sintácticas y entre las analíticas formas morfológicas; traducido por J. P.] (ZAVADIL y ČERMÁK, 2010), las construcciones con el predicado verbonominal «tvoří jistou přechodnou oblast mezi volnými spojeními a frazeologickými jednotkami » [se encuentran en mitad de camino entre conjuntos libres y conjuntos fraseológicos; traducido por J.P.] (PISÁRČIKOVÁ, 1997 : 145). Desde un punto de vista más general, se podría reflexionar acerca de la existencia de sinonimia total entre un contenido expresado por una construcción con el predicado verbonominal y otra expresada por un verbo. En cualquier caso, se nos plantea la cuestión de si ese problema puede ser contestado de manera tan sencilla, o no. En el hispanismo checo fue ya DUBSKÝ (1984a : 15), quien se ocupó de ese tema y quien lo relaciona con el carácter más explicicativo del español especializado ${ }^{4}$ frente al checo:

« el español da cierta preferencia a modos de decir explícitos, utilizándose en semejantes casos verbos de apoyo como elementos de transición o relacionales que explicitan el enunciado ",

con lo cual, en realidad, se podría admitir que ambos recursos de expresión funcionarán como sinónimos, diferenciándose uno del otro por su diferente función estilística (20).

20. [...] quedando el acusado de hacerle entrega del coche en un plazo de 6 días. [...] no hizo entrega del vehículo al comprador. [ENTREGAR]

En cualquier caso, ese problema merecería otra investigación más profunda, de la cual no podemos ocuparnos aquí. De todas formas, se puede considerar los predicados verbonominales como un caso muy progresivo del componente estilísticamente marcado del lenguaje administrativo, cuyo uso no siempre se supedita a los factores estilísticos o textuales, sino también a factores de carácter morfosintáctico.

\subsubsection{Sinonimia de componentes constantes (terminología)}

Indudablemente, la base fundamental del lenguaje especializado es su propia terminología, es decir, un conjunto de palabras vinculadas a una esfera concreta de

\footnotetext{
${ }^{4}$ Ejemplos de la tendencia generalmente más explícita del español frente al checo, al que en relación con los textos especializados advierte KRÁlová (2003 : 79), los podemos observar incluso en el lenguaje jurídico administrativo, y eso no solamente en los textos muy formalizados como por ejemplo en las "partes descriptivas" (hechos probados) de las sentencias: [...] se presentó, pidiendo ayuda y teléfono, en la vivienda de finca próxima habitada por la familia compuesta por [...], sino también en los textos menos formalizados de contenido jurídico (noticias de Internet): Gracias a la colaboración ciudadana, han sido detenidos cinco hombres de edades comprendidas entre los 28 y 40 años e incautados en total 2.768 kilos de hachís.

http://www.cadenaser.com/espana/articulo/detenidos-narcotraficantes-28-toneladas-hachismarbella/csrcsrpor/20140829csrcsrnac_5/Tes; [Fecha de consulta: 29/08/2014].
} 
la actividad humana. Son numerosas las opiniones que pretenden definir el concepto de término, sin embargo casi todas en principio coinciden cuando dicen que el término tiene un contenido y extensión bien delimitados (DUBSKÝ, 1977 : 165), o según AlCARAZ (2004 : 210) que:

"Los términos se diferencian de las unidades léxicas del lenguaje común en que aquellos son monosémicos mientras que éstas son polisémicas, ambiguas, transportan connotaciones, poseen sinónimos y su significado se activa dentro de un contexto, mientras que los términos no necesitan del contexto, ya que se entienden dentro de una teoría o de un campo de saber ",

o según CALVI (2010 : 25) que:

" [...] las unidades terminológicas cumplen la misión de transmitir un contenido especializado preciso dentro de un campo determinado; se caracterizan por la monosemia y se utilizan en función denotativa ».

Es indiscutible que el rasgo principal de la terminología del lenguaje especializado es, sin duda alguna, su precisión, univocidad y monosemia. Esta característica es aún más evidente en caso del género jurídico, ya que cada imprecisión terminológica puede causar serios problemas a las partes intervinientes del proceso, tanto materiales como humanos. Parece entonces lógico que todos esos rasgos se inclinen a refutar la existencia de sinonimia entre lo que aquí decidimos llamar componentes constantes. Sin embargo, como veremos a continuación, el problema de (no) existencia de sinonimia dentro de la terminología especializada no es siempre tan claro como pueda parecer. El léxico especializado (terminología) puede ser plasmado desde diferentes puntos de vista: su origen (latinismos, helenismos, arabismos, fuentes modernas, etc.), su estructura (unidades simples y compuestas, palabras derivadas y parasintéticas) y el grado de su especialidad (vocabulario técnico, semitécnico, general de uso frecuente en Derecho), tal y como lo enseñan ALCARAZ y HugHES (2002). Para los fines del presente trabajo consideramos útil partir de su concepto relativo al grado de especialidad del vocabulario especializado ${ }^{5}$, ya que opinamos que el grado de especialidad de cierto término pueda influenciar su capacidad de ser reemplazado por un sinónimo.

\footnotetext{
${ }^{5}$ En el ambiente lingüístico checo es conocida otra clasificación de vocabulario jurídico presentada por TOMÁŠEK (2003 : 48), quien distingue entre "grupo A" - vocabulario utilizado solamente en el lenguaje común y desconocido por el lenguaje jurídico (alegría, belleza), "grupo C" - vocabulario utilizado solamente en el lenguaje jurídico y desconocido para el lenguaje común (heredero ilegítimo), "grupo B1" - vocabulario que es común al lenguaje común y lenguaje jurídico, pero que por lo menos por una parte dispone de cierto significado jurídico (pena, tribunal), y finalmente "grupo B2" - vocabulario neutral, es decir, tales palabras que se utilizan en textos jurídicos, a pesar de su nulo significado jurídico (día, mujer). Muy inspiradora consideramos también la teoría de Mayoral (MAYORAL ASENSIO, 2004 : 57) quien dice «Vemos que en la definición de una categoría o clase aparecen elementos que forman parte claramente de la misma, elementos que todos identifican como pertenecientes a esa categoría, elementos que cumplen con todas las condiciones establecidas para la pertenencia a ella, y elementos periféricos que forman parte de límites difusos entre categorías contiguas y solapadas ».
} 
Es muy probable que la sinonimia desempeñe un papel significativo también en caso de vocabulario que, a pesar de no estar jurídicamente connotado, se utiliza frecuentemente en textos jurídicos - es el caso del así llamado vocabulario general de uso frecuente en Derecho (AlCARAZ y HugHES, 2002; TOMÁŠEK, 2003): día, hombre. Debido a que esas palabras no aluden a realidades extralingüísticas precisamente delimitadas y jurídicamente definidas, tal y como podremos observar en caso del componente constante, no se podrá descartar relativamente alta frecuencia de casos de sinonimia entre tales unidades léxicas del lenguaje administrativo-jurídico. Sin embargo, en varias ocasiones hemos podido observar que los autores de un texto jurídico (jueces, abogados, legisladores, etc.) aprovechan esporádicamente la posibilidad de mejorar estilísticamente "su producto", de modo que el mecanismo más frecuente para mantener la cohesión textual en un texto jurídico es la repetición de la misma palabra (21).

21. Tras despertarse el procesado ató las manos y piernas de María con cinta adhesiva transparente, dirigiéndose primero, a realizar rápida carga en zona de [...], y, a continuación en [...] de dicha localidad, donde debía efectuar otra carga, desatando antes de llegar las manos y piernas de María [...].

De tal manera podemos explicar también una frecuencia relativamente alta de los así llamados sinónimos contextuales (FILIPEC, 1955) en los textos de orientación jurídica: María Fátima $\rightarrow$ perjudicada, denunciante, Marie Nováková $\rightarrow$ matka nezletilé [madre de la menor de edad] y cierta tendencia hacia la invariabilidad de esas anáforas nominales ${ }^{6}$ utilizadas dentro de un texto jurídico (vid. 21).

Una importante parte del vocabulario jurídico está, no obstante, compuesta de las unidades terminológicas por excelencia (tecnicismos) que forman parte del así llamado centro del área especializado. Generalmente, se trata de palabras muy técnicas, conceptualmente ligadas con la realidad extralingüística que describen. Son palabras que aluden a un contenido concreto, bien delimitado; y su presencia en el lenguaje común es prácticamente descartada ya que su verdadero significado es bien comprensible exclusivamente por los especialistas de la materia. De tal modo, en el lenguaje especializado no son sustituibles por un sinónimo, sin embargo en el lenguaje menos especializado (por ejemplo cuando se usan en los medios de comunicación), es posible que, para asegurar su comprensión por no expertos, sean sustituidas por un sinónimo más conocido, pero menos exacto, o su significado sea parafraseado con otras palabras menos técnicas. Como ejemplos concretos podemos mencionar las palabras jurídicas como: výprosa (precario), výpůjčka (comodato), zápiojčka (préstamo),etc. En general, algunos de esos tecnicismos puros son muy poco frecuentes en el lenguaje general, por ejemplo el CORPES XXI registra tan solo 7 casos en 6 documentos del uso de la palabra comodato en España y ningún caso del sustantivo precario en España ${ }^{7}$, en la lengua checa dos de ellas výprosa (precario) y zápưjčka (préstamo) tienen un

\footnotetext{
${ }^{6}$ Acerca del problema de anáforas nominales vid. trabajo de PEŠEK (2012).

${ }^{7}$ REAL ACADEMIA ESPAÑOLA: Banco de datos (CORPES XXI) [en línea]. Corpus del español del siglo XXI. http://www.rae.es [Fecha de consulta 12/07/2014]
} 
matiz arcaico, ya que fueron reintroducidas en la jurisdicción checa tras la última modificación del Código Civil en 2014 y la diferencia exacta entre las dos es conocida solo por los que se especializan en materia jurídica. Es común que algunas de esas voces técnicas sean propias incluso del lenguaje no especializado, tal como podemos observar en el caso de las voces výpůjčka y préstamo cuyos significados no prestan mayores dificultades ni a los menos expertos en la materia concreta, con lo cual ya, de acuerdo con ALCARAZ y HUGHES (2002) podríamos hablar de palabras semitécnicas, utilizadas también en contextos menos especializados $^{8}$. A base de lo expuesto pretendemos aludir a una de las características de la terminología especializada consistente en que un término cuanto más es utilizado en el lenguaje no especializado, tanto más es probable que se convierta (desde el punto de vista no profesional) en palabra polisémica (heterónima), cuyos significados incluirán para no expertos incluso los significados que tales voces no implican en el lenguaje especializado.

Con el fenómeno anteriormente mencionado (si bien desde otra perspectiva) está vinculada una situación opuesta, a la cual alude en relación con el lenguaje especializado FILIPEC (1955) - la así llamada «desinonimización », o sea, « situación cuando dos palabras que se han considerado sinónimos, dejan de serlo a partir de un momento determinado ». No pocas veces suelen ser « desinonimizadas » en el lenguaje jurídico tales palabras, que desde la perspectiva de no expertos, no atraen ningún significado jurídicamente notable (por ejemplo en español estafa $\because:$ fraude o en checo lhưta (plazo) $::$ doba (duración), en lo cual radica un gran obstáculo para la traducción especializada. Este fenómeno tiene lugar, por ejemplo, en caso cuando varía la realidad extralingüística y la extensión de los conceptos que la expresan. Tal situación es relativamente frecuente en el lenguaje jurídico administrativo, ya que los diferentes cambios sociopolíticos pueden tener como consecuencia cambios legislativos y la introducción de nuevos conceptos.

Desde la óptica traductológica, consideramos los anteriores casos igualmente tramposos como la situación que se produce a la hora de "uso no-terminológico" de la terminología especializada, tal y como vemos a continuación (22-23): voces que denotan a realidades extralingüísticas concretas, pero cuyo uso no queda restringido exclusivamente al lenguaje especializado (22), sino los podemos ver utilizar también por usuarios no expertos en contextos no necesariamente especializados (23):

22. La Policía Foral ha denunciado recientemente a un vecino de la zona pirenaica como presunto autor de un delito contra la salud pública por tráfico de drogas. Se trata de U.G.M., de 21 años, quien se encuentra en libertad a la espera de ser llamado a declarar por el juzgado de Primera Instancia e Instrucción número 2 de Aoiz.

\footnotetext{
8 Desde la perspectiva contrastiva, es interesante que en español la voz "más general" (o hiperonímica) de las tres sería "préstamo", mientras que en la lengua checa lo sería výpuijčka (comodato). Nos explicamos tal "comportamiento asimétrico" por las diferencias sociales, políticas e históricas que favorecieran usos de ciertas voces a otras (por ejemplo durante el comunismo en nuestro país no era muy extendido pedir prestado dinero - zápůjčka).
} 
23. Los simpatizantes del exjefe del Estado denuncian que el procesamiento forma parte de una campaña para acabar con su carrera política.

Como otros ejemplos de casos de (no) sinonimia de los componentes constantes del vocabulario jurídico nos servirán semitecnicismos imputado, acusado, o sea, las palabras que, a diferencia del antes mencionado denunciar, no implican necesariamente dos significados diferentes (uno especializado y otro no especializado), sino que llegan a ser de factum sinónimos, al ser utilizados en contextos menos especializados, tal y como han observado ALCARAZ y HUGHES (2002: 97):

« [...] muchas de las unidades léxicas que son sinónimas en el lenguaje común, en el jurídico no siempre lo son ».

Su reemplazo es muy habitual por ejemplo en el estilo periodístico donde esas palabras ya no deben mantener obligatoriamente su exacto contenido especializado. Precisamente esas palabras son, entonces, unas de las más problemáticas desde la perspectiva de su comprensión y percepción, ya que aunque parezcan sinónimas, en esencia no lo son. Su implementación al lenguaje común y su uso incorrecto, o mejor dicho uso no terminológico, es muy evidente en los medios de comunicación, donde se describe la realidad jurídica apoyándose en el vocabulario especializado de la disciplina (en este caso, de vocabulario jurídico). A continuación, sigue un ejemplo de uso "no terminológico" del componente constante del vocabulario jurídico (semitecnicismos) acusar e imputar, ambos provenientes del mismo artículo periodístico'; que muy bien ilustran la situación cuando dos términos que deberían (desde la perspectiva jurídica) aludir a dos diferentes fases del procedimiento penal, en el estilo menos especializado son empleados en calidad de dos sinónimos:

24. El juez de Estepona manda a prisión a Kukucova por la muerte de su exnovio.

Casi dos meses después del crimen, la joven eslovaca fue acusada formalmente de homicidio.

Casi 55 días después del crimen, Mayka Kukucova se ha sentado cara a cara con el juez de Estepona que instruye el caso sobre la muerte de Andrew Bush, el empresario británico de 48 años que fue hallado muerto en su villa con varios disparos en la cabeza. Tras prestar declaración ayer durante toda la mañana, la modelo eslovaca de 24 años y expareja del fallecido salió del Juzgado de Primera Instancia e Instrucción número 1 imputada por un presunto delito de homicidio. [...]

Insistimos en que parecidos casos de sinonimia del componente constante del vocabulario jurídico están supeditados a un determinado grado de especialización del texto en el cual se utilizan, ya que los textos especializados dirigidos a un público no experto en una materia (por ejemplo noticias criminales en el periódico) admiten un manejo menos estricto con el léxico especializado (o "elementos terminológicos" del lenguaje especializado). Desde la perspectiva

\footnotetext{
${ }^{9}$ http://www.laopiniondemalaga.es/costa-sol-occidental/2014/05/30/juez-estepona-manda-prisionkukucova/681014.html [Fecha de consulta: 07/08/2014]
} 
contrastiva (en primer lugar, al tener en cuenta la necesidad de transmitir exactamente el significado de un término de una lengua a otra) tal situación puede dificultar el proceso traslativo, tal y como apunta, entre otros, BARCELó MARTÍNEZ (2010 : 41):

"Tanto la sinonimia como la polisemia son figuras del lenguaje que pueden plantear grandes obstáculos en el proceso translativo ».

Prácticamente al lado de las categorías anteriores se encuentran casos, que podrían ser denominados como casos de sinonimia total en el estilo jurídico. Con eso nos referimos en el lenguaje jurídico al hecho de existencia de varias formas para designar la misma realidad, de las cuales una es de carácter internacional, y la otra es la variante adaptada: lex - ley, corpus delicti - cuerpo del delito, alibi coartada. Son varios los lingüistas que consideran dichos casos como una prueba de la existencia de sinonimia total del vocabulario especializado. Sin embargo, hay que ser consciente de que los últimos avances en la lingüística, vinculados ante todo a la lingüística de corpus, descartan la existencia de ese tipo de sinonimia total, remitiendo a diferente frecuencia, colocabilidad y distribución de cada miembro de tal doblete (ČERMÁK, 2010 : 264).

\section{Sinonimia extralingüística. Estilo funcional: administrativo-jurídico; lenguas estudiadas: checo y español}

En el sentido más amplio podemos comparar el proceso traslativo, es decir, « la búsqueda de un equivalente adecuado en una lengua meta », con « la elección estilística de un sinónimo a la hora del proceso de la redacción de un texto concreto », tal y como apunta KLÉGR (2004). Vamos a dejar en esta ocasión aparte la idoneidad o no del término sinonimia extralingüística, ya que somos conscientes de los argumentos existentes que nieguen su implementación en la lingüística. Bajo la etiqueta de sinonimia extralingüística, siguiendo al autor mencionado, comprenderemos un peculiar tipo de sinonimia existente entre palabras que denotan la misma realidad extralingüística en varias lenguas (a modo de simplificar, la sinonimia extralingüística es la búsqueda de un respondente ideal para un concepto de una y otra lengua). Partiendo de ese marco teórico intentaremos brevemente enseñar la manifestación de dicho fenómeno en (1) versiones paralelas de noticias contenidas en el portal informativo VoxEurop.eu y (2) artículos de prensa checa relativos a acontecimientos extranjeros. En las páginas anteriores hemos señalado que algunas voces jurídicas que denotan la realidad jurídica, admiten sinonimia en contextos jurídicos menos especializados (imputado, procesado, acusado). Desde el punto de vista lingüístico, se trata en la mayoría de casos del componente constante de lenguaje especializado (palabras técnicas y semitécnicas), cuya sinonimia extralinguiística se ve afectada por el factor extralingüístico, o sea, por la diferente concepción de la realidad extralingüística en el ambiente jurídico checo y español. Tal diferencia se manifiesta en el así denominado "anisomorfismo", o sea, "lack of symmetry in the patterns of things in nature of life" (ALCARAZ, 2004) - evidente por ejemplo es el caso de procesado que alude a una fase del procedimiento penal desconocida por 
la legislación correspondiente checa. ${ }^{10}$. Como un ejemplo concreto de lo que acabamos de decir nos podrá servir el delito del cual ha sido imputado en mayo de 2014 el ex presidente francés Sarkozy, y las diferentes maneras de su traducción por los medios de comunicación checos (25):

25. El expresidente francés Nicolás Sarkozy ha sido imputado en la madrugada del miércoles por "corrupción activa", tráfico de influencias y encubrimiento de la violación del secreto profesional

- Bývalý francouzský prezident Nicolas Sarkozy byl v noci na středu formálně obviněn z úplatkářství a vyzrazení služebního tajemství.

- Bývalý francouzský prezident Nicolas Sarkozy byl v noci z úterý na středu formálně obviněn z korupce, úplatkářství a porušení služebního tajemství.

- Sarkozy je podezřelý ze zneužití pravomoci a porušení tajemství probíhajicího vyšstřování.

En ese caso es, por cierto, muy bien visible el grado de cómo el anisomorfismo puede afectar al vocabulario tan especializado: probablemente debido a la inexistencia del delito equivalente en la jurisdicción checa, los diferentes medios de comunicación eligen distintas formas para traducirlo al checo. Se puede ver muy claramente como las diferentes soluciones aplicadas difieren entre sí y cómo consiguen llegar a malinterpretar la realidad jurídica. Sostenemos la opinión que sufren una mayor predisposición a manifestaciones anisomórficas precisamente las esferas del lenguaje especializado, cuyo léxico es estrechamente vinculado con la situación sociopolítica y cultural (por ejemplo lenguaje jurídico), fenómeno observado ya por ALCARAZ (2004 : 205).

Otra situación se produce en caso de parejas aparentemente claras de tipo imputado $::$ obviněný, acusado $::$ obžalovaný, que teniendo en cuenta la intensión y extensión de sus significados, desde la perspectiva contrastiva no deberían suponer mayores dificultades, ya que aluden a realidades extralingüísticas concebidas en ambos sistemas jurídicos de manera prácticamente comparable. En cualquier caso, la situación real es distinta, tal y como demuestran los casos mencionados a continuación (26-29): por ejemplo, es imposible desde la perspectiva jurídica que se acuse (26-27) a una persona antes de que se la impute (28-29) un delito:

titulares de febrero de $2013^{11}$

26. $84 \%$ lidí chce obžalobu princezny Cristiny

Podle průzkumu veřejného mínění, jehož výsledky zveřejnil španělský deník El Mundo, si většina Španělů myslí, že princezna Cristina, dcera krále Juana Carlose, by měla být obžalována v korupční kauze, do které je zapleten její manžel.

Iñaki Urdangarin byl obviněn ze zpronevěry, podvodů a daňových úniků, ke kterým používal jako zástěrku společnost Aizoon, kde je jeho žena 50\% vlastníkem.

\footnotetext{
${ }^{10}$ Es lógico que en esos casos (procesado) sea inevitable aplicar, según la tradición traductológica, alguna de las técnicas de traducción existentes, que nos ayuden a superar dicha dificultad. Nos hemos dedicado a dicho problema parcialmente en nuestro artículo (PEŠKOVÁ, $2011: 15$ ).

${ }^{11} \mathrm{http}: / /$ www.voxeurop.eu/es/content/news-brief/3391601-el-84-cree-que-el-juez-deberia-imputar-lainfanta-cristina [Fecha de consulta: 08/08/2014]
} 
27. El $84 \%$ cree que el juez debería imputar a la Infanta Cristina

Una encuesta publicada por el diario revela que una mayoría de los españoles creen que la Infanta Cristina debería ser imputada en el caso de corrupción en el que está envuelto su marido.

Iñaki Urdangarin está acusado de malversación de fondos, fraude y evasión fiscal utilizando una empresa, Aizoon, de la cual la Infanta Cristina detenta el 50\%.

titulares de junio 2014

28. Španělský soud ve středu obvinil sestru španělského krále Felipeho VI., infantku Cristinu, z praní špinavých peněz a daňových podvodů.

29. El juez José Castro acaba de hacer público el auto de acusación del caso Urdangarin en el que, tal y como adelantó EL MUNDO el lunes pasado, sienta en el banquillo a la Infanta Cristina por delito fiscal y blanqueo de capitales.

Esos casos demuestran que, además, incluso en caso de sinonimia extralingüística es válido que las voces, cuyos significados no admiten sinonimia en contextos especializados, se emplean como sinónimos en estilos funcionales menos especializados. Por otro lado, hay que darse cuenta que tales respondentes ("sinónimos extralingüísticos") no funcionarán en calidad de respondentes adecuados a la hora de traducir un texto de grado de especialidad más alto (sentencia, legislativa, etc.).

\section{Conclusiones}

En este punto, pretendemos recapitular las principales conclusiones a las que hemos llegado. Hemos visto que la sinonimia tiene su lugar incluso en un lenguaje tan especializado como lo es el lenguaje jurídico-administrativo. Sin embargo, su empleo en textos especializado, se supedita en muchos casos a ciertas tendencias propias al lenguaje especializado, e impropias al lenguaje no especializado. Para poder analizar dicho problema más detenidamente hemos distribuido las unidades léxicas de un texto jurídico en: componentes potenciales y componentes constantes, y hemos observado los factores más significativos que impiden o favorecen la existencia de sinonimia y polisemia en textos jurídicos. En lo que se refiere al componente potencial hemos observado que entre los factores "clásicos" (preferencias individuales del autor, grado de la cortesía, las convenciones del estilo funcional cuestionado), destaca en el ámbito jurídico un número bastante alto de "estructuras estereotipadas" que muy raramente admiten ser reemplazadas con otra construcción sinónima. Hemos observado asimismo que muchas veces la cuestión de las relaciones semánticas dentro del ámbito jurídico se subordina al grado de especialidad del texto. Se puede concluir, por lo tanto que, desde una óptica más general, la sinonimia de los componentes potenciales del lenguaje jurídico no ha de ser considerada como "defectuosa", ya que sus posibles consecuencias adversas se hacen patentes ante todo en el nivel estilístico. Sin embargo, hemos visto igualmente que el empleo "descontrolado" de sinonimia en caso del componente constante ya podría conllevar consecuencias nefastas, significantes ante todo desde la perspectiva de la comprensión del texto y su posible calificación jurídica. Y para acabar, vimos que el problema se extiende aún más si lo concebimos desde la perspectiva contrastiva, ya que a parte de los factores ya mencionados debemos contar con diferencias socio-culturales que muchas veces causan cierta asimetría entre la terminología existente en dos 
lenguas para describir la misma realidad jurídica (anisomorfismo), lo cual al final complica el proceso traslativo y la interpretación exacta de un término de una lengua a otra.

\section{BIBLIOGRAFÍA}

Alcaraz VARÓ Enrique ; Hughes Brian (2002), El español jurídico, Barcelona, Ariel.

AlCARAZ VARÓ Enrique (2004), Anisomorfismo y lexicografía técnica, in: GONZÁleZ L. ; HeRNúÑEZ P. (eds), Las palabras del traductor, Bruselas, EsLetra, p. 201-220.

BARCEló MARTínez Tanagua (2010), La polisemia y la (no)sinonimia en el proceso de enseñanza-aprendizaje del lenguaje jurídico, Anales de Filología Francesa, ${ }^{\circ} 18$, p. 29-44.

Calvi Maria Vittoria (2010), Las lenguas de especialidad en español, Roma, Carocci.

ČERMÁK František (2010), Lexikon a sémantika, Praha, Nakladatelství Lidové noviny.

DUBSKÝ Josef (1984a), El valor explícito de las construcciones verbales y verbonominales del español, Español Actual, p.13-20.

DUBSKÝ Josef (1984b), Aspectos lingüísticos de las cartas comerciales. Volumen preparado por José Polo, Madrid, Coloquio.

DUBSKÝ Josef (1989), Základy španělské lexikologie pro překladatele a tlumočníky. 2. přeprac. vyd. Praha, Státní pedagogické nakladatelství.

FILIPEC Josef (1955), Rozbor odborného stylu a jeho vnitřní diferenciace, Slovo a slovesnost 16, Praha, p. 37-52.

KLÉGR Aleš (2004), Vnitrojazyková a mezijazyková synonymie [Intralingual and Interlingual Synonymy], philologica.net [en línea], 2004-01-13. Disponible en: http://philologica.net/studia/20040113000002.htm [Fecha de consulta 201409-22].

KOPECKIJ Leontij (1935), O lexikálním plánu hospodářského jazyka, Slovo a slovesnost 1, Praha, p. 120-122.

KRÁlOVÁ Jana (2003), Fiesta 3: španělština pro střední a jazykové školy, Plzeň, Fraus.

MAYORAL ASENSIO Roberto (2004), Lenguajes de especialidad y traducción especializada. La traducción jurídica, in: GonZALO GARCÍA Consuelo ; Valentín GARCÍA YEBRA (eds), Manual de documentación y terminología para la traducción especializada, Madrid, Arco/Libros.

PEŠEK Ondřej (2012), Progressions thématiques et anaphorisation. L'apport informationnel des procédés de reprise, Écho des études romanes, vol. VIII, num. 1, České Budějovice, Filozofická fakulta Jihočeské univerzity, p. 207217.

PEŠKOVÁ Jana (2011), Límites de la traducción de textos jurídicos del español al checo, in: Králová J. (éd.), Posibilidades y Límites de la Comunicación Intercultural. Ibero-Americana Pragensia. Supplementum 27/2011, Univerzita Karlova v Praze, p. 193-197. 
PISÁRČIKOVÁ Mária (1977), Synonymické vzt’ahy pri ustálených spojeniach typu „dat' súhlas“, Slovenská reč, 42, p. 144-153.

RADIMSKÝ Jan (2010), Verbo-nominální predikát s kategoriálním slovesem, České Budějovice, Universitatis Bohemiae Meridionalis.

REAL ACADEMIA ESPAÑOLA: Banco de datos (CORPES XXI) [en línea]. Corpus del español del siglo XXI. Disponible en: http://www.rae.es. [Fecha de consulta 12/07/2014].

TOMÁŠEK Michal (2003), Překlad v právní praxi, Praha, Linde.

ZAVADIL Bohumil, Petr ČERMÁK (2010), Mluvnice současné španělštiny: lingvisticky interpretační př́stup, Praha, Karolinum. 